مقارنة تاثير المعزز الحيوي المستورد (Biomin) والمحلي

في الاداء الانتاجي لفروج اللحم (Iraqi Probiotic)

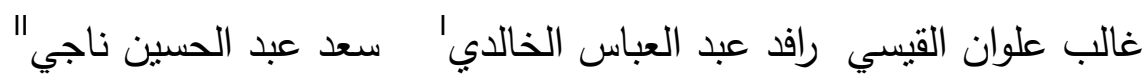

\title{
الخلاصة
}

انشارت الدراسات الحديثة الى ان اضافة المعززات الحيوية للعلائق تؤدي الى احداث توازن مايكروبي

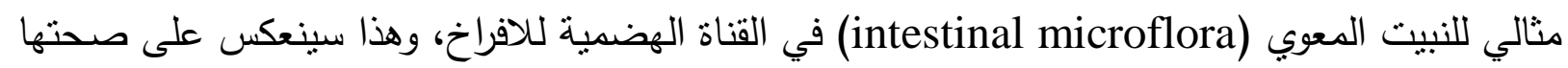
وادائها وصفاتها الانتاجية. الدراسـة الحالية استهدفت مقارنـة تاثير المعزز الحيوي المستورد (Biomin) والمحلي (Iraqi Probiotic) في الاداء الانتاجي لفروج اللحم. استخدمت بالدراسة 500 فرخ لحم سلالة

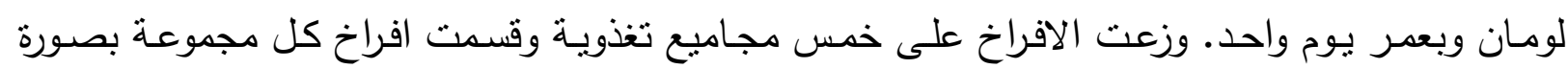
عشوائية على مكررين وكانت المجاميع كما يلي:-

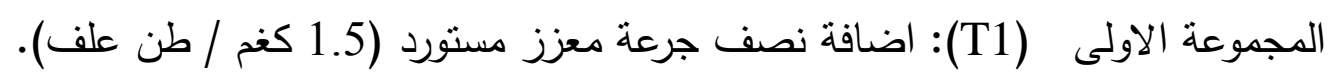

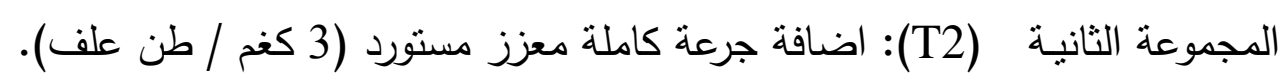

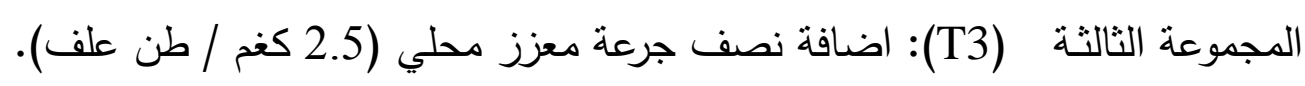
المجموعة الرابعة (T4): اضافة جرعة كاملة معزز محلي (53): اضغة كغة / (T) طن علف).

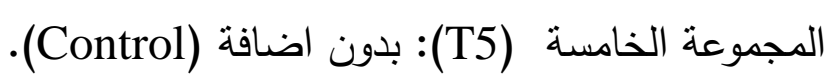

تم وزن الافراخ اسبوعيا وكذلك حسبت كميات العلف المستهلكة ونسب الهلاكات وكفاءة تحويل الغذاء بنهاية كل اسبوع. وعند عمر النسويق (8 اسابيع) تم ذبح 5 طيور من كل مكرر لغرض استخراج نسب التبات التصافي ونسب الاحشاء الداخلية الماكولة.

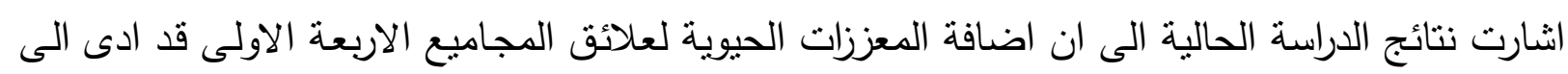

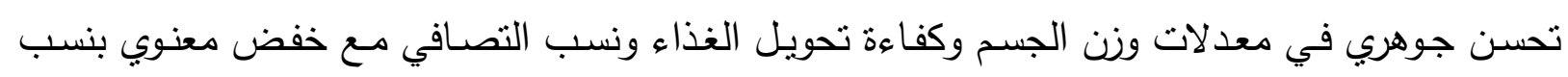

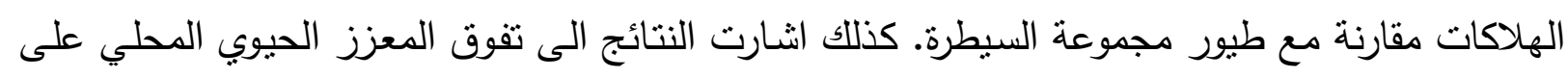
المعزز المستورد في معظم الصفات المدروسة عند اضافته بنصف جرعة (2.5 كغم / طن علف).

\section{The Comparative Effect of Imported (Biomin) and Local Iraqi Probiotic on Broiler Performance}




\section{Galib. A. AL-Kaissi Rafid, A. AL-Khalidi ${ }^{\mathrm{I}} \quad$ S.A. Naji ${ }^{\text {II }}$}

\section{Summary}

Recent reports shown that the supplementation of the broiler ration with a probiotic leads to an ideal microbial balance in the intestinal microflora of their gastrointestinal tract. Such balance, however, would reflect on their health and performance. The aim of the present study was to compare the effect of two probiotic products, Biomin and Iraqi probiotic, on the broiler performance characteristics. A total of 500 Lohman broiler chicks, one day old, were randomly distributed into five dietary groups as follow:

$\mathrm{T}_{1}$ : chicks fed on diet with half dose of Biomin (1.5 Kg/ Ton diet).

$\mathrm{T}_{2}$ : chicks fed on diet with full dose of Biomin. ( $3 \mathrm{Kg} / \mathrm{Ton}$ diet)

$\mathrm{T}_{3}$ : chicks fed on diet with half dose of Iraqi probiotic. $(2.5 \mathrm{Kg} / \mathrm{Ton}$ diet $)$

$\mathrm{T}_{4}$ : chicks fed on diet with full dose of Iraqi probiotic. $(5 \mathrm{Kg} / \mathrm{Ton}$ diet $)$

$\mathrm{T}_{5}$ : chicks fed slandered diet. (Control)

Results obtained from the present study showed that the supplementation of the diets with probiotic, biomin or Iraqi probiotic, had significantly $(\rho>0.05)$ improved the final body weight, feed conversion and dressing percentage and decreased mortality. However, Iraqi probiotic seemed to be more effective than biomin in most of these treats. Furthermore, the use of a half dose of Iraqi probiotic $(2.5 \mathrm{Kg} /$ ton feed $)$ seemed to be better than the full dose.

\section{المقدمة}

ان مصطلح المعزز الحيوي Probiotic مشتق من كلمنين يونانيتين وهما Pro و biotic والتي والتي تعني لاجل الحياة (For life) وهي عكس كلمة Antibiotic والتي تعني مضاد الحياة (Against life) (1) ولقد عرف الباحثون المعزز الحيوي على انه نوع او اكثر من الاحياء المجهرية المفيدة سواء كانت جراثيم (Bacteria) او خمائر او اعفان او خليطا منها.

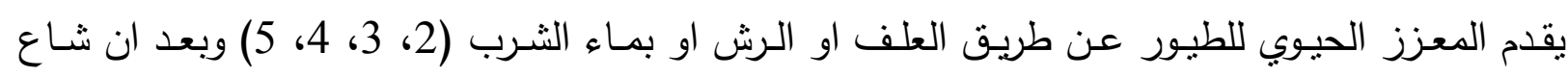

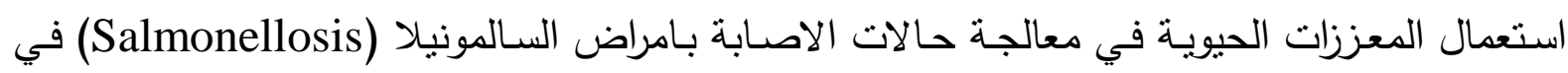

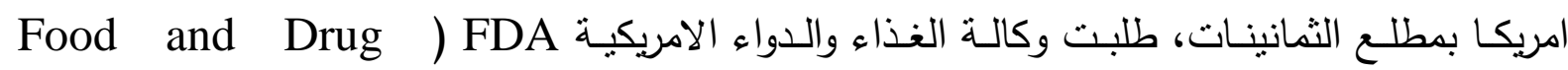

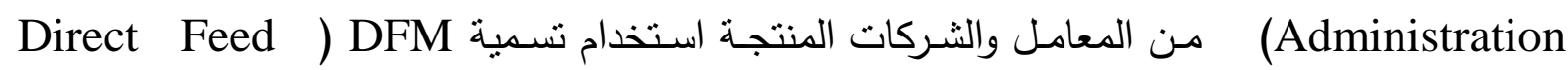
(Microbs 
(1) • ان تزايد الاهتمام حول ظهور الاثار السلبية الجانبية للمضـادات الحياتية وظهور بعض السـلالات

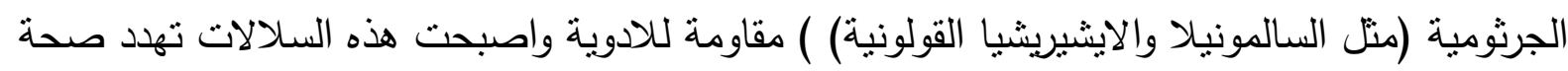
الانسان (6، 7) هذا النوع اعطى زخم كبير لاستخدام المعززات الحيوية لتقليل الاصيابات المرضية وتقليل

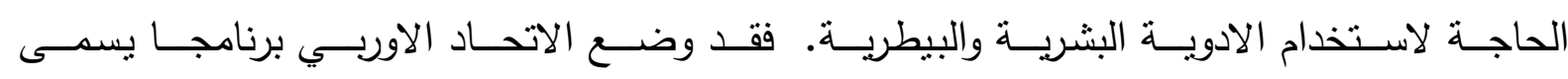

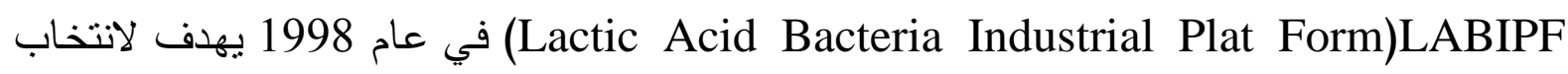
سلالات من بكتريا حامض اللبنيك واستخدامها في المعزز الحيوي لتعزيز صحة الانسان. ولقد ثبت ان

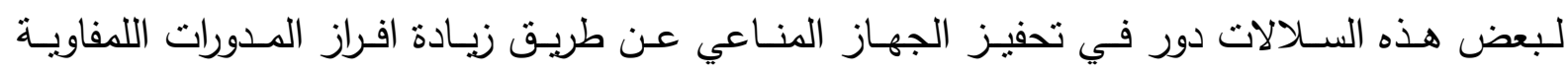
(Cytokines) وبالدواجن فقد ثبت بان للمعززات الحيوية دور في تحسين معدلات وزن الجسم وكفاءة تحويل الغذاء (11،

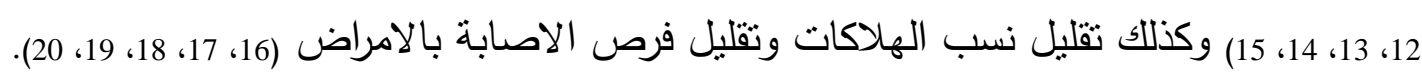
التجربة الحالية استهدفت اجراء مقارنـة لتاثير نوعين من المعززات الحيويـة (المستورد والمحلي) وتاثير فئري

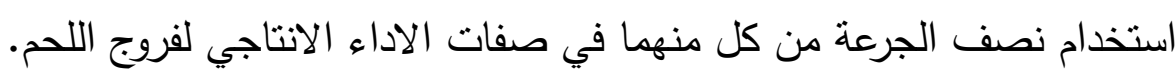

\section{المواد وطرائق العمل}

نفذت هذه الدراسة في احد حقول الطيور الداجنة في منطقة المدائن للمدة من 5/3 ولغاية 6/30

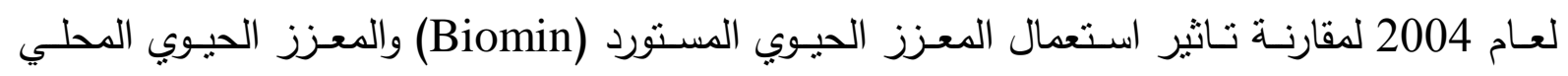
(Iraqi Probiotic)

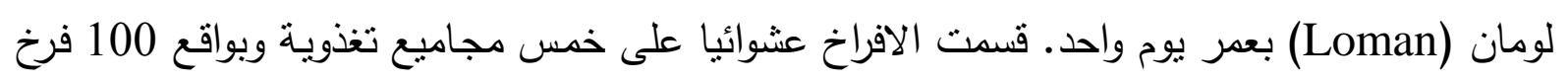

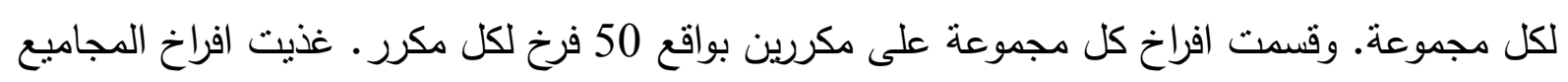

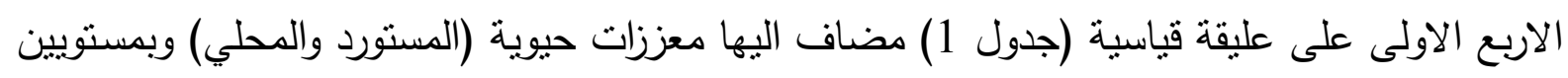

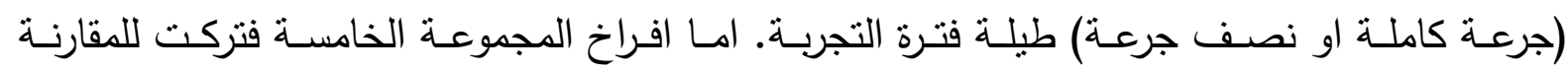
(Control)

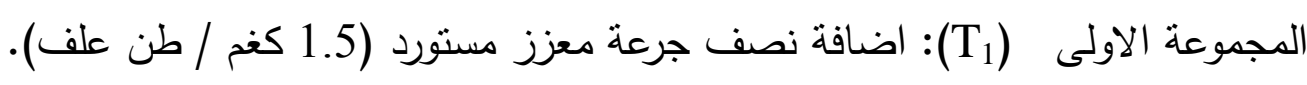

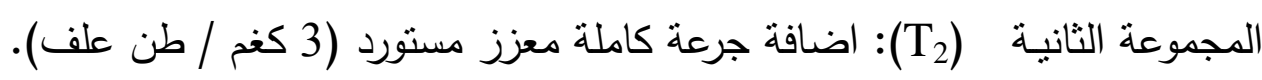
المجموعة الثالثة (T33): اضافة نصف جرعة معزز محلي (T2.5 كغم / طن علف).

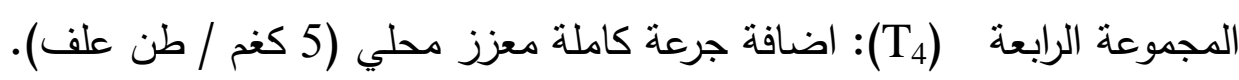
المجموعة الخامسة (T55): بدون اضافة (Control):

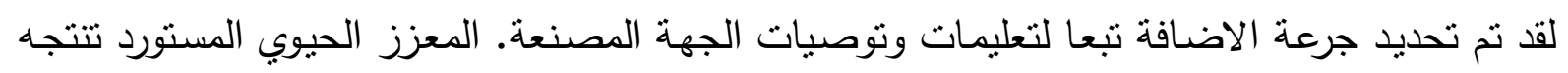
شركة استرالية وهو مطروح بالاسواق المحلية باسم تجاري Biomin IMB52 وهو يحتوي على ما لايقل 


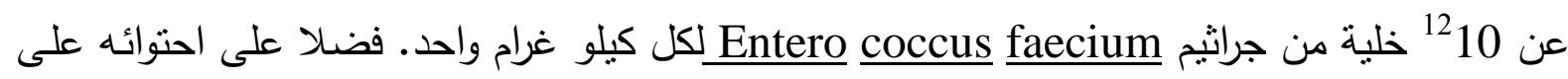
مادة Fructo - Oligosaccharide التي تعتبر كسابق حيوي (Prebiotic). امـا المعزز الحيوي عزي

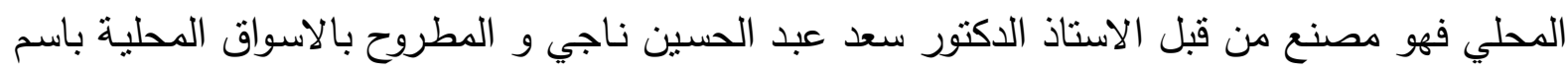
بروبايوتلك العراق (Iraqi Probiotic) ويحتوي الكيلو غرام الواحد من هذا المعزز الحيوي على ما يلي: Lactobacillus acidophilus Bacillus subtilus عشرة بليون خلية من جراثيم

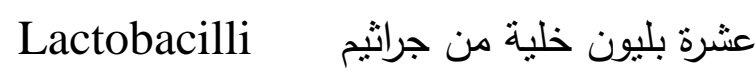

Saccharomyces cerevesiae

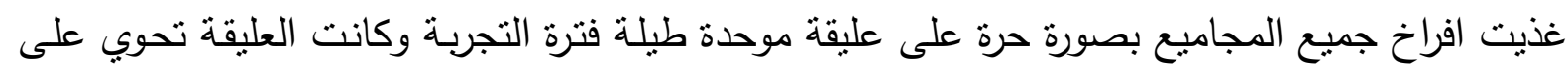

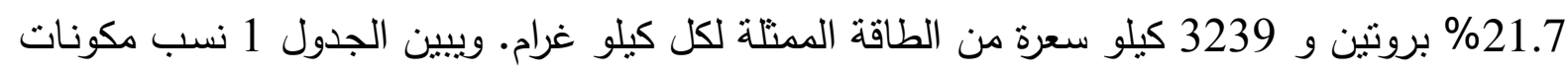

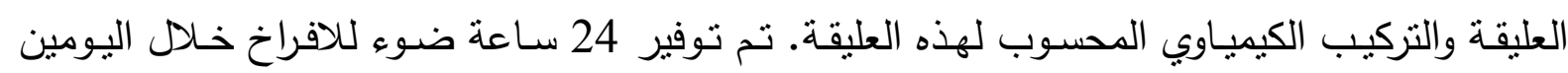
الاوليين من عمرها. بعد ذلك استخدم نظام الاضاءة المتقطعة (2 ساعة ضوء : ساعة ظلام) طيلة فترة

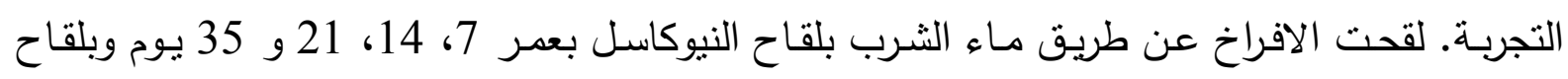

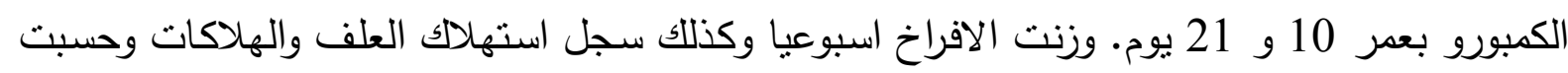

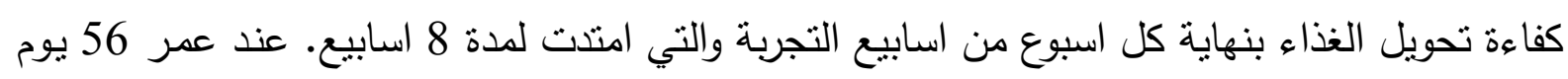

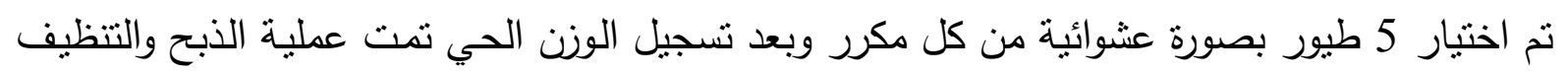

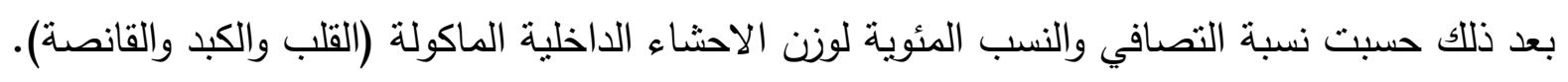

جدول (1) نسب مكونات العليقة المستخدمة في تغذية افراخ التجربة

\begin{tabular}{|c|c|}
\hline نسبتها (\%) & مكونات العليقة \\
\hline 48 & ذرة صفراء \\
\hline 10 & حنطة \\
\hline
\end{tabular}




\begin{tabular}{|c|c|}
\hline 25 & كسبة فول الصويا ( 44\% بروتين ) \\
\hline 10 & مركز بروتيني حيواني (50 \% بروتين ) \\
\hline 6 & زيت نباتي ( زيت زهرة الثمس ) \\
\hline 0.55 & حجر كلس ( $\left.\mathrm{Caco}_{3}\right)$ \\
\hline 0.35 & ملح الطعام ( Nacl ) \\
\hline 0.1 & خليط فيتامينات ومعادن * \\
\hline 100 & 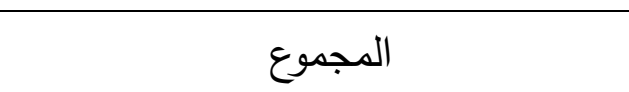 \\
\hline 21.5 & البروتين الخام (\%) \\
\hline 3239 & الطاقة الممتلة (كيلو سعرة /كغم علف) \\
\hline 1.12 & اللايسين(\%) \\
\hline 0.40 & المثيونين (\%) \\
\hline 1.35 & الكالسيوم (\%) \\
\hline 0.65 & الفسفور (\%) \\
\hline
\end{tabular}

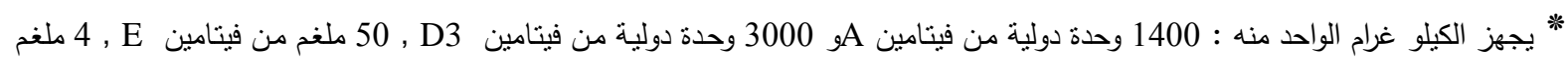

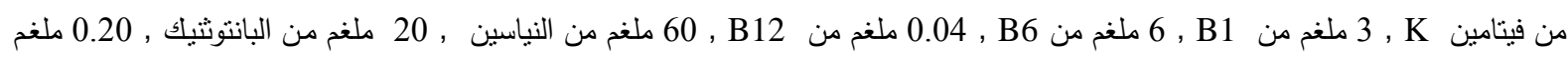

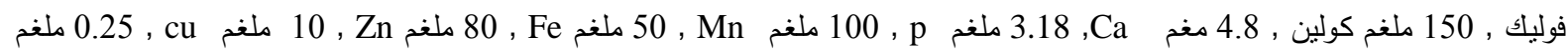

استخدم التصميم العشوائي الكامل (Completely Randomized Design) في التحليل الاحصائي لبيانات التجربة لمعرفة ناثير نوع المعزز الحيوي وكمية الجرعة في الاداء الانتاجي لفروج اللحم واستخدم

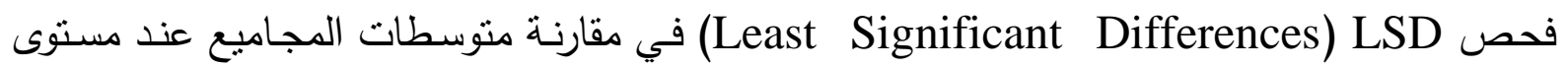
0.05 وباستخدام التحليل الاحصائي الجاهز SAS

\section{النتائج والمناقشة}

يتبين من الجدول 2 ان اضافة كلا النوعين من المعززات الحيوية وبكلتا الجرعتين قد ادت الى

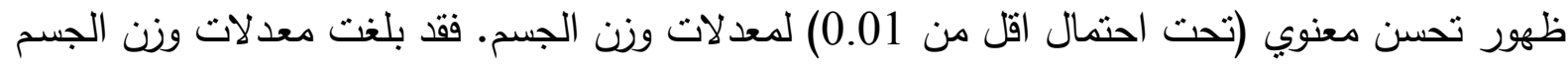
عند عمر (56 يوم) للمجاميع الاربعة الاولى 1962 و 1966 و 2074 و 1956 غرام على التوالي 
وكانت هذه المعدلات اعلى بصورة عالية المعنوية من معدل وزن الجسم لطيور مجموعة السيطرة والبالغ

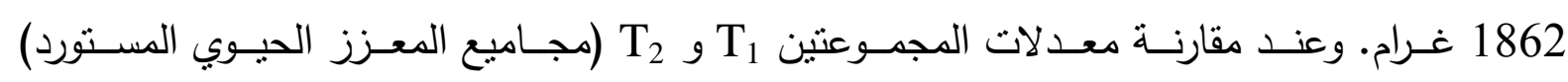

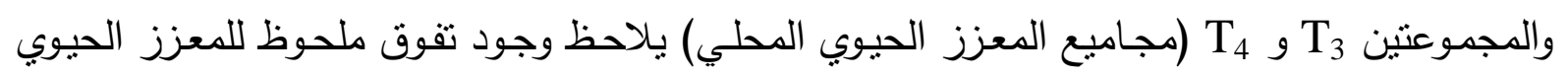

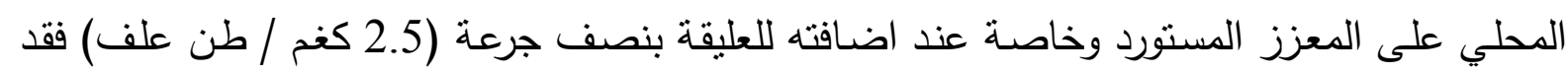

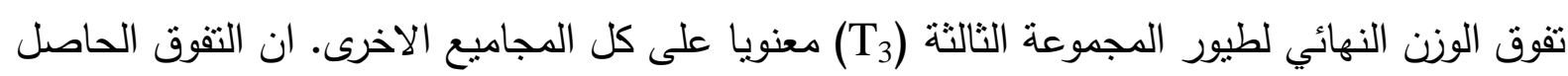

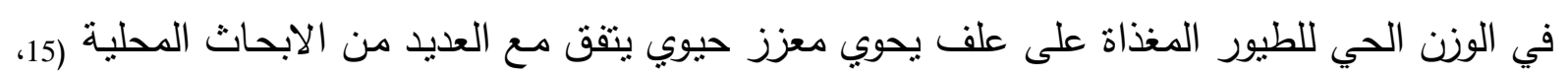
22) والابحاث الاجنبية (23، 24، 25) ذلك لان الإحياء المجهرية المستخدمة كمعززات حيوية تلعب دورا مهما

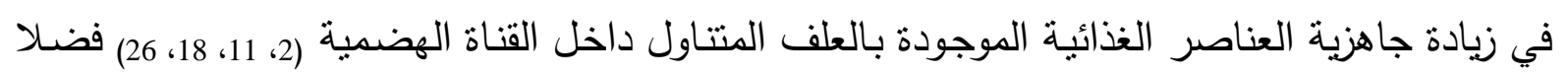

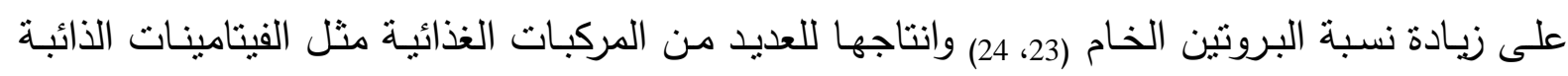

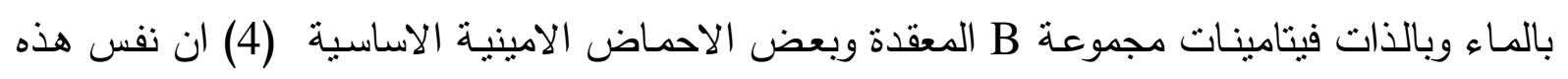

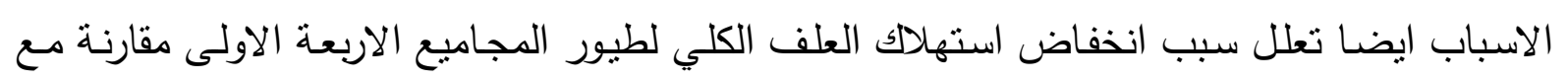
مجموعة السيطرة (T5) وكذلك التحسن الكبير الذي طرأ على معامل تحويل الغذاء لهذه المجاميع وكما موضح بالجدوليين 3 و 4.

الثكل1 يبين تاثير اضافة المعزز الحيوي المستورد والمحلي في نسبة الهلاكات الكلية لفروج اللحم

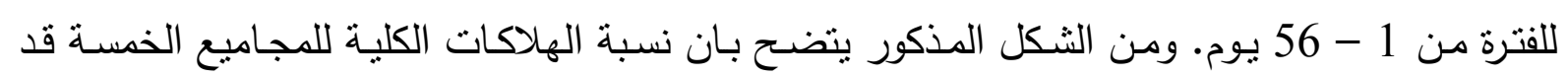

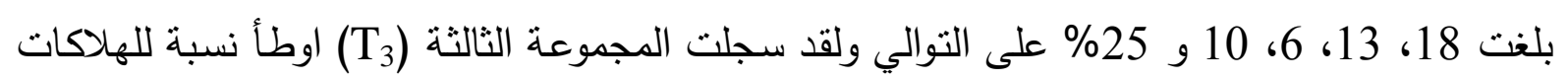

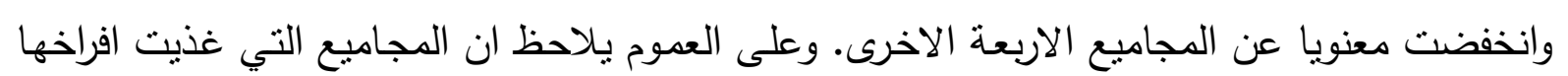
على علائق مضاف اليها معززات حيوية قد انخفضت فيها نسبة الهلاكات مقارنة مع مجموعة السيطرة.

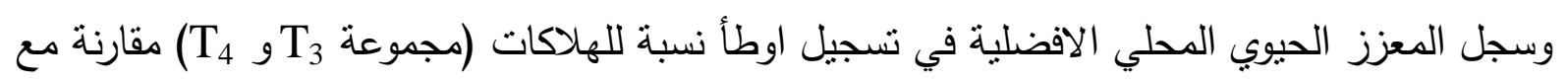
نسبة الهلاكات للمعاملتنين T و T T التي غذيت طيورها على على عليقة مجهزة بالمعزز الحيوي المستورد

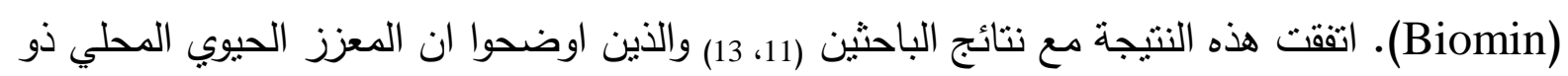

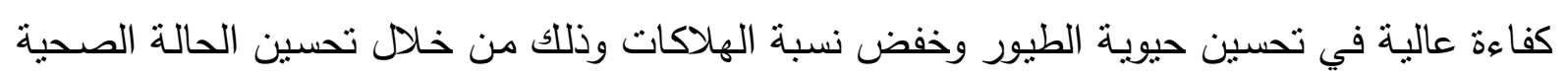

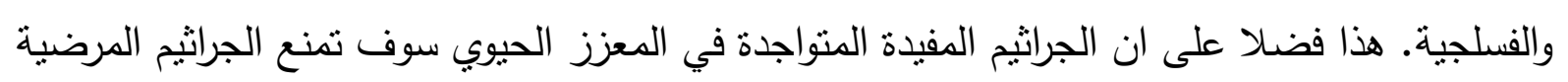

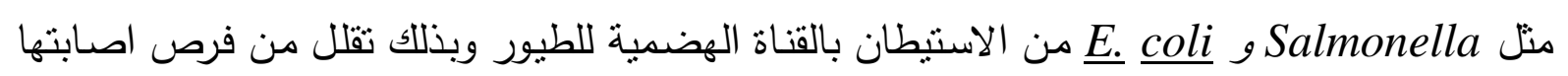
بالامراض (1، 6، 17) الثكل 2 يبين ناثثر اضافة نسب من المعزز الحيوي المستورد والمحلي في نسبة التصافي مـع

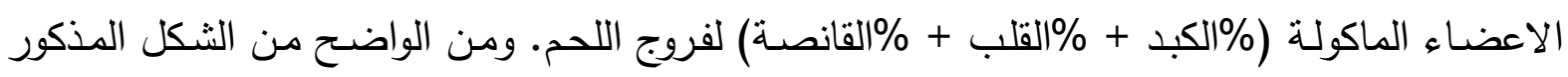

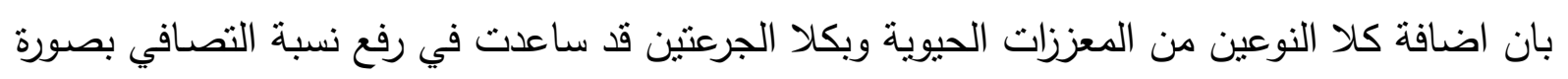




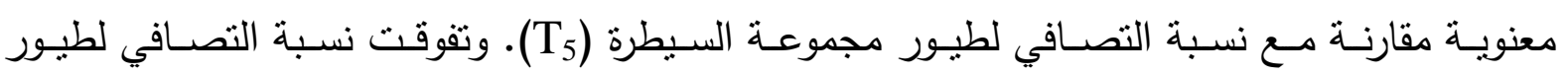
المجموعة الثالثة (T3) معنويا على نسبة التصافي لطيور مجموعة السيطرة وطيور المجاميع الثلاثة

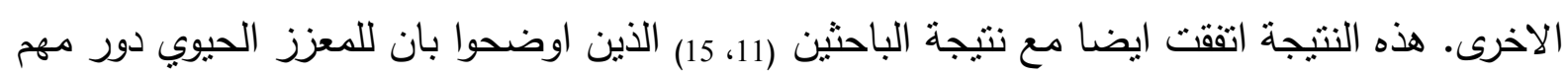

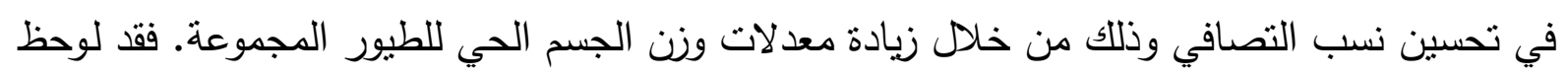

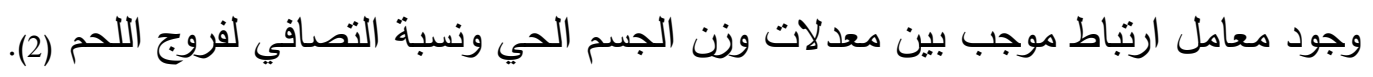
ان التقوق الذي سجله المعزز الحيوي المحلي (Iraqi Probiotic) على المعزز الحيوي المستورد (Biomin)

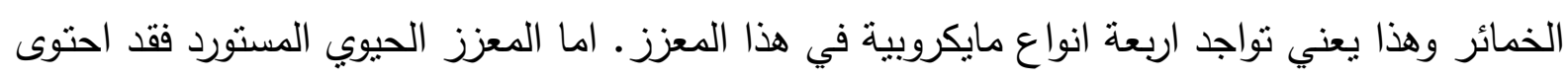

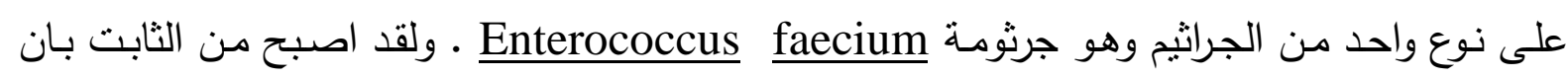

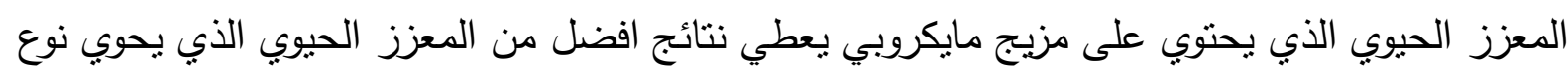

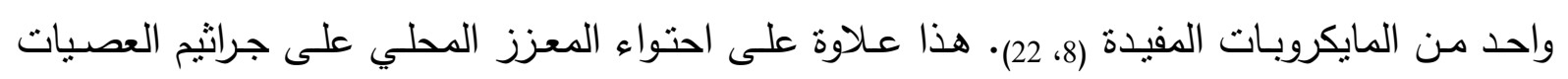

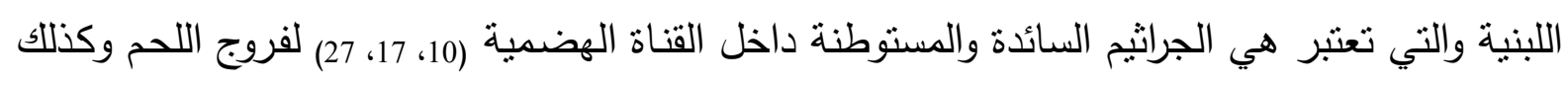

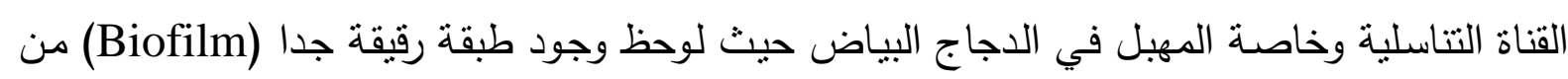

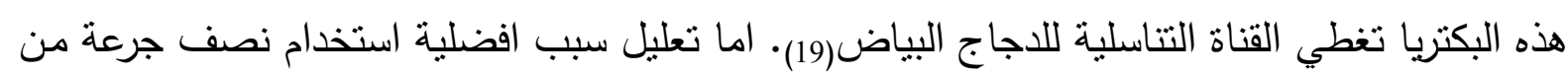
المعزز الحيوي المحلي على الجرعة الكاملة فهو غير معروف والاجابة عليه تتنظر ابحاث مستقبلية لاحقة ان شاء الله تعالى. 
الثكل (8) تاثير اضافة نسب من المعزز الحيوي المحلي والمستورد في نسبة الهلاكات الكلية لفروج اللحم للددة من 1-56 يوماً .

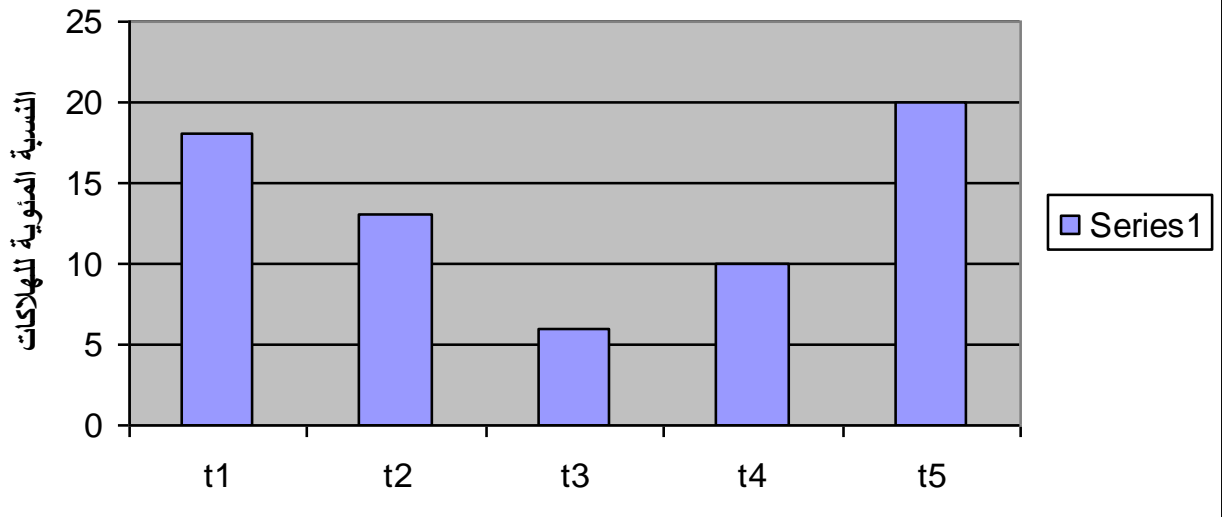




\section{Refarance}

1. Miles RD and SM Bootwala. (1991). Direct-Fed Microbial in animal production "avian" pp. 117-146. In: Direct-Fed Microbial in animal production. A review of literature. National Feed Ingredients Association, West Des Moines, Iowa, U.S.A.

2. Abdulrahim SM, MS Y Haddadin, EAR. Hashlamoun and RK Robinsion (1996). The influence of Lactobacillus acidophilus and bacitracin on Layer performance of chickens and cholesterol contents of plasma and egg yolk. Br. Poult. Sci. 37: 341 -346.

3. Schneitz C (1993). Development and evaluation of a competitive exclusion product for poultry. Ph. D. Thesis, University of Helsinki, Department of Veterinary Medicine, Helsinki, Finland.

4. Rantala M (1974a). Cultivation of bacterial flora able to prevent the colonization of Salmonella infants in the intestines of broiler chickens and its use. Acta. Pathol. Microbiol. Scand. Sect. B., 82 : 75 - 80.

5. Rantala M (1974b). Nitrovin and tetracycline: a comparison of their effect on Salmonella in chicks. Br. Poult. Sci., 15: 299 - 303.

6. Reuter G. (2001). Probiotics - Possibilities and Limitations of their application in food, animal feed, and in pharmaceutical preparations for man and animals. Ber. Mun. Tier. Woch. 114: $410-419$.

7. WHO, (1997). Antibiotic use in food producing animals must be curtailed to prevent increased resistance in humans, World Health Organization press, release WHO / 73, 20 October.

8. Adawi DS Ahrne and G. Molin (2001). Effects of different probiotic strains of Lactobacillus and Bifid bacterium on bacterial translocation and Liver injury in an acute liver injury model. Int. J. Food Microb. 70 (3): 213220.

9. Bedford M (2000). Removal of antibiotic growth promoters from poultry diets: implications and strategies to minimise subsequent problems, Review. Worlds Poult. Sci. J. 56(4):347-365.

10.Reque, E. D., A. Pandey, S. G. Franco and C. R. Soccol. (2001). Isolation, identification and physiology study of Lactobacillus fermentum LPB for use as probiotic in chikens. Braz. J. Microbiol. 31 (4): 303 - 307.

$$
\begin{aligned}
& \text { 11. التميمي, عمار طالب ذياب. (2004). دراسة مقارنة لتأثير استعمال الزنك باستراين والمعزز }
\end{aligned}
$$

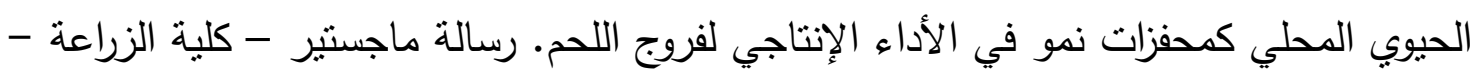

$$
\begin{aligned}
& \text { جامعة بغداد. }
\end{aligned}
$$


12. الدليمي, جيهان عبد الستار سلمان. (2000). استخدام الكحول الاثيلي لعزل بكتيريا حامض

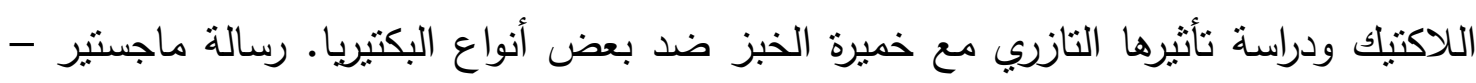
كلية الزراعة - جامعة بغداد.

13. الضنكي، زياد طارق محمد. ناجي سعد عبد الحسين و عبد المطلب كريم العذاري. (2005).

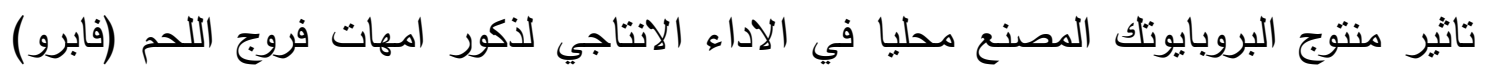
والمغذاة على نسب مختلفة من الثعير . مقبول للنشر في مجلة الانبار للعلوم الزراعية. المجلد

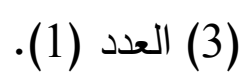

14. الضنكي، زياد طارق محمد. ناجي سعد عبد الحسين و سعاد خضير الخفاجي. (2002). ناثير

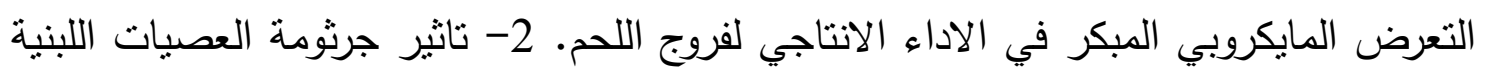
في الاداء الانتاجي والاستجابة المناعية وبعض صفرات الاداء الانيكي الدم لفروج اللحم. مجلة العلوم الزراعية

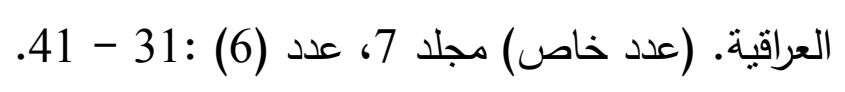

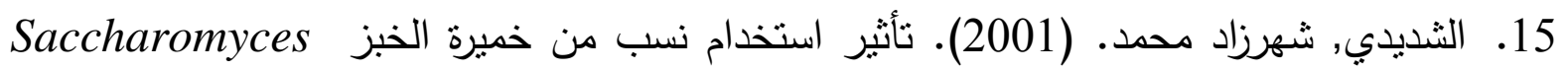
cerevisiae ماجستير - كلية الزراعة - جامعة بغداد.

16. الضنكي، زياد طارق محمد. ناجي سعد عبد الحسين. (2000). ناثير التعرض المايكروبي المبكر بخميرة Saccharomyces cerevisiae على الاداء الانتاجي والاستجابة المناعية لفروج اللحم. مجلة العلوم الزراعية العراقية. العدد الثاني مجلد 31، 373 - 384. 17. العبيدي, ابتسام جواد ـ (2001). استخدام جراثيم العصيات اللبنية كمعزز حيوي ضد الإية الإصابة بجراثيم اثريكيا القولونية والسالمونيلا. رسالة ماجستير - كلية الطب البيطري البئي - جامعة بغداد.

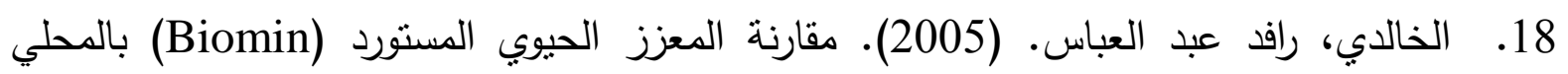
(Iraqi Probiotic) رسالة ماجستير - كلية الطب البيطري - جامعة بغداد.

19. Miyamoto T T Horie, Fujiwara T and E. Baba. (2000). Lactobacillus flora in the cloaca and vaginea of hens and its inhibitory activity against Salmonella entrids in vitro. Poultry Sci. 79: $7-11$.

20. Simmering R and Blaut B (2001). Pro and prebiotics the tasty guardian anegls. A Review. Appl. Microbiol. Biotechnol 55 (1): 19 - 28.

21. SAS, (1996). SAS User's guide: statistical system, Inc. Cary, NC. USA. 22. الموشلي, ابراهيم بدر الدين • (2001) ـ تقييم الاداء الإنتاجي لفروج اللحم المعامل بأنواع مختلفة من البكتيريا المفيدة. رسالة ماجستير - كلية الزراعة - جامعة بغداد. 
23. Kahraman R, Oxpinar H, Abas I and Ckutay H. (2000). Effects of probiotic and antibiotic on performance of broilers. Arch. Geflugekd. 64 (2): 70-74.

24. Pietras, M. (2001). The effect of probiotics on selected blood and meat parameters of broiler chickens. J. Anim. Feed Sci. 10: 297 - 302.

25. Zulkifli T, Abdullah $\mathrm{N}$ and $\mathrm{Y}$. W. Ho. (2000). Growth performance and immune response for two commercial broiler strains fed diets containing Lactobacillus cultures and oxytetracyclin under heat stress condition. Br. Poult. Sci. 41: 593 - 597.

26. Jin, L.Z,Y.W.Ho;N.Abdullah and S.Jalaludin. (2002). Digestive and bacterial enzyme activities in broilers fed diets supplemented with lactobacillcultures. Poultry sci, 79:886-891.

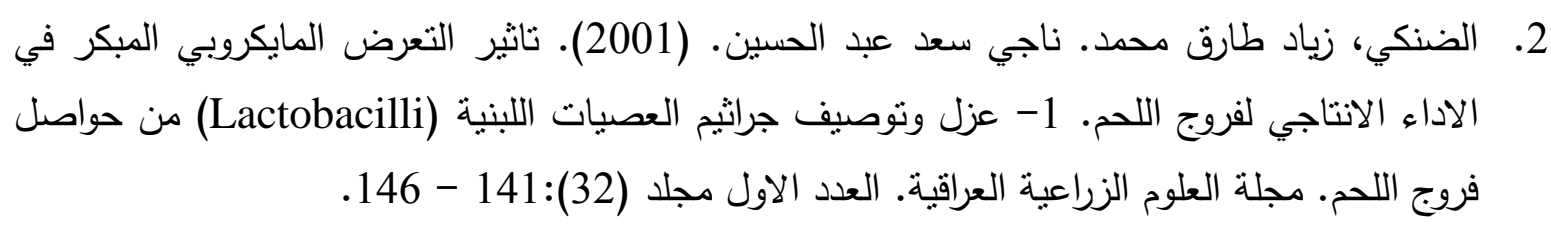

